\title{
Lung function after preterm birth: development from mid-childhood to adulthood
}

\author{
Maria Vollsæter, ${ }^{1,2}$ Ola Drange Røksund, ${ }^{2}$ Geir Egil Eide, ${ }^{3,4}$ Trond Markestad, $^{1,2}$ \\ Thomas Halvorsen ${ }^{1,2}$
}

- Additional material is published online only. To view please visit the journal online (http://dx.doi.org/10.1136/ thoraxjnl-2012-202980).

${ }^{1}$ Department of Clinical Science, Section for Pediatrics, University of Bergen, Bergen, Norway

${ }^{2}$ Department of Pediatrics, Haukeland University Hospital, Bergen, Norway

${ }^{3}$ Centre for Clinical Research, Haukeland University Hospital, Bergen, Norway

${ }^{4}$ Department of Global Public Health and Primary Care, Lifestyle Epidemiology Research Group, University of Bergen, Bergen, Norway

\section{Correspondence to} Dr Maria Vollsæter, Department of Pediatrics, Haukeland University Hospital, Bergen N-5021, Norway; maria.vollsaeter@helse-bergen. no, mvollsaeter@gmail.com

Received 8 November 2012 Revised 17 April 2013 Accepted 2 May 2013 Published Online First 7 June 2013

\section{SLinked}

- http://dx.doi.org/10.1136/ thoraxjnl-2012-203079 - http://dx.doi.org/10.1136/ thoraxjnl-2013-203836

To cite: Vollsæter $M$, Røksund OD, Eide GE, et al. Thorax 2013;68:767-776.
ABSTRACT

Background As a result of advances in perinatal care, more small preterm infants survive. There are concerns that preterm birth and its treatments may harm pulmonary development and thereby lead to chronic airway obstruction in adulthood.

Objective To assess the development of spirometric lung function variables from mid-childhood to adulthood after extreme preterm birth.

Methods Two population-based cohorts born at gestational age $\leq 28$ weeks or with birth weight $\leq 1000 \mathrm{~g}$ performed lung function tests at 10 and 18 and at 18 and 25 years of age, respectively, together with matched term-born controls. The results are presented as z scores, normalised for age, sex and height. Longitudinal development was compared for groups born at term and preterm, split by a history of absence $(n=20)$, mild $(n=38)$ or moderate/severe $(n=25)$ neonatal bronchopulmonary dysplasia (BPD).

Results The preterm-born cohorts, particularly those with neonatal BPD, had significantly lower forced expiratory volume in $1 \mathrm{~s}$ and mid-expiratory flow than those born at term at all assessments ( $z$ scores in the range -0.40 to -1.84 ). Within each of the subgroups the mean $\mathrm{z}$ scores obtained over the study period were largely similar, coefficients of determination ranging from 0.64 to 0.82 . The pattern of development for the BPD subgroups did not differ from each other or from the groups born at term (tests of interaction).

Conclusions Airway obstruction was present from mid-childhood to adulthood after extreme preterm birth, most evident after neonatal BPD. Lung function indices were tracking similarly in the preterm and term-born groups.

\section{INTRODUCTION}

Advances in perinatal care have markedly increased the prospects of survival for infants born extremely preterm (EP). ${ }^{1}{ }^{2}$ However, there is an increasing awareness that EP birth carries a risk of poor long-term pulmonary outcome. ${ }^{3}{ }^{4}$ Gas exchange in these tiny neonates must take place in developmentally fetal lungs, characterised by ongoing differentiation and growth. ${ }^{5}$ Survival usually requires comprehensive and invasive treatments including assisted ventilation and long periods of oxygen supplementation. ${ }^{1}$ Thus, preterm birth and the necessary respiratory support may disturb fine-tuned programmed patterns of fetal lung development, potentially with long-lasting negative effects on lung function. ${ }^{5}$

\section{Key messages}

What is the key question?

- Does the development of lung function from childhood to adulthood after extremely preterm birth differ from that of peers born at term?

\section{What is the bottom line?}

- Airway obstruction was observed throughout the study period for those born preterm and was most pronounced after neonatal bronchopulmonary dysplasia; however, lung function trajectories were basically parallel in all subgroups.

\section{Why read on?}

- This is the first controlled and population-based report on the longitudinal development of lung function from childhood to adulthood after extremely preterm birth, and the data underline the risk of early onset of COPD in subsets of this population.

The most significant pulmonary complication of preterm birth was termed bronchopulmonary dysplasia (BPD) by Northway in $1967 .{ }^{6}$ Although definitions have changed and the clinical expression is generally less severe today, BPD continues to pose a major risk to these children. ${ }^{7}$ The incidence of BPD after EP birth seems to have settled in the range of $50 \%$, defined by the need for oxygen therapy or assisted ventilation at 36 weeks' postmenstrual age. ${ }^{8}$

The phenotype of BPD after early childhood is poorly described. There are no human biopsy studies and structural characteristics must be inferred from functional investigations. Airway obstruction has repeatedly been reported for children born preterm, and those with BPD generally do worse. ${ }^{4}$ Development of lung function from childhood to adulthood is debated and not well understood, and longitudinal studies are few. ${ }^{9-11}$ Normally, after childhood growth, lung function attains a stable plateau before onset of a physiological age-related decline. ${ }^{12}$ The maximum level obtained, the duration of the plateau and the rate of the decline predict if and when obstructive pulmonary disease will occur in later life.

The aim of this study was to compare the development of lung function from mid-childhood to adulthood in subjects born EP with that of peers born at term. For this purpose, two population- 
based cohorts of subjects born EP and matched control subjects born at term were examined on two occasions, enabling construction of lung function trajectories from 10 to 18 years and from 18 to 25 years of age.

\section{METHODS}

\section{Subjects and study design}

The preterm-born participants consisted of two populationbased cohorts born in 1982-1985 and 1991-1992 at gestational age $\leq 28$ weeks or with birth weight $\leq 1000$ g by mothers living within a defined area of the Western Norway Regional Health Authority. Subjects were considered enrolled when admitted to the neonatal intensive care unit (NICU) at Haukeland University Hospital, the only institution in the region admitting children eligible for this study. The senior medical staff was largely unchanged in the two inclusion periods. ${ }^{13}$ For those born in 1991-1992, exogenous surfactant (Exosurf) was prescribed as for selective administration in the Osiris trial. ${ }^{14}$ Gestational age at birth was determined according to identical algorithms in both inclusion periods. ${ }^{13}$ A diagnosis of BPD was assigned if supplemental oxygen was required at 28 postnatal days (mild BPD) or postmenstrual age $\geq 36$ weeks (moderate/severe BPD). ${ }^{15}$ Neonatal data were obtained from hospital charts, equally and systematically recorded and prospectively tabulated for the two inclusion periods. Other relevant background data were obtained from questionnaires filled in by the subjects and/or parents at the time of the examinations.

One individually matched term-born control subject was recruited at the first visit in 2001 for each preterm-born participant. The temporally nearest term-born child of the same sex and with birth weight 3-4 kg (Norwegian 10-90 percentiles) was identified from hospital birth protocols. If that subject declined, the next born subject was approached, and so on.

Subjects were first seen in 2001-2002 and subsequently in 2008-2009 at the cardiopulmonary laboratory in the Pediatric Department, Haukeland University Hospital. The same paediatrician and respiratory physiologist performed all examinations at both visits with similar equipment.

\section{Lung function measurements}

Spirometry was performed with a Vmax spirometer (SensorMedics, Anaheim, USA) at both visits, according to standard quality criteria. ${ }^{16}$ Forced expiratory volume in $1 \mathrm{~s}\left(\mathrm{FEV}_{1}\right)$, forced vital capacity (FVC) and forced expiratory flow at $25-75 \%$ of $\mathrm{FVC}\left(\mathrm{FEF}_{25-75}\right)$ were recorded and standardised to $\mathrm{z}$ scores and percentages of predicted using the all-age reference equation, correcting raw data for differences in age, sex and height. ${ }^{17}$

\section{Statistical methods}

Differences between independent groups were assessed with the independent sample $t$ test or Mann-Whitney $U$ test for continuous variables and the Pearson $\chi^{2}$ test for categorical outcomes. Associations between lung function values obtained in 20012002 and 2008-2009 were assessed with simple linear regression analyses, and prediction equations and coefficients of determination $\left(\mathrm{R}^{2}\right)$ were provided for $\mathrm{FEV}_{1}$ and $\mathrm{FEF}_{25-75}$. Lung function development was analysed with the mixed linear regression model of SPSS with respect to age and group (control, EP non-BPD, mild BPD and moderate/severe BPD), including interaction terms. ${ }^{18}$ The model allows for inclusion of subjects seen only once. Backwards stepwise linear regression models were constructed to explore associations for $\mathrm{FEV}_{1} \mathrm{z}$ scores at visit 2 versus background variables listed in table 1 . Within the pretermborn groups, similar regression models were applied to explore associations for $\mathrm{z}-\mathrm{FEV}_{1}$ at visit 2 versus gestational age at birth, birth weight, days on ventilator, treatment with postnatal and antenatal corticosteroids and surfactant therapy. The study was originally designed to have $90 \%$ power to detect differences exceeding $7.5 \%$ in $\mathrm{FEV}_{1}$ between the two preterm and termborn cohorts, given a significance level of 0.05 . The full study had $85 \%$ power to detect changes in $\mathrm{z}-\mathrm{FEV}_{1}$ of 0.6 from visit 1 to visit 2, providing the same significance level. All analyses were performed with SPSS V.18.0 (SPSS, Chicago, Illinois, USA).

\section{RESULTS}

Subjects

A total of 130 eligible neonates were admitted to the NICU in the two inclusion periods and $86(66 \%)$ were alive at the first

Table 1 Background variables for 83 subjects born extremely preterm with and without neonatal bronchopulmonary dysplasia (BPD) and 81 term-born control subjects

\begin{tabular}{|c|c|c|c|c|c|}
\hline \multirow[b]{2}{*}{ Mean (SD) age (years) } & & \multicolumn{2}{|c|}{ 1991-1992 cohort } & \multicolumn{2}{|c|}{ 1982-1985 cohort } \\
\hline & & $10.5(0.4)$ & $17.8(0.4)$ & $17.7(1.2)$ & $24.9(1.2)$ \\
\hline Total N & $\begin{array}{l}\text { Control } \\
\text { Preterm }\end{array}$ & $\begin{array}{l}35 \\
35\end{array}$ & $\begin{array}{l}29 \\
31\end{array}$ & $\begin{array}{l}46 \\
46\end{array}$ & $\begin{array}{l}40 \\
43\end{array}$ \\
\hline Maternal smoking in pregnancy & $\begin{array}{l}\text { Control } \\
\text { Preterm }\end{array}$ & $\begin{array}{r}9(26) \\
13(37)\end{array}$ & - & $\begin{array}{l}10(22) \\
22(48)^{*}\end{array}$ & - \\
\hline Current self-reported smoking & $\begin{array}{l}\text { Control } \\
\text { Preterm }\end{array}$ & - & $\begin{array}{l}5(17) \\
1(3)\end{array}$ & $\begin{array}{l}14(30) \\
15(33)\end{array}$ & $\begin{array}{r}8(20) \\
17(40)\end{array}$ \\
\hline Allergyt & $\begin{array}{l}\text { Control } \\
\text { Preterm }\end{array}$ & $\begin{array}{l}8(23) \\
9(26)\end{array}$ & - & $\begin{array}{l}20(44) \\
13(28)\end{array}$ & - \\
\hline Wheeze last 12 months & $\begin{array}{l}\text { Control } \\
\text { Preterm }\end{array}$ & $\begin{array}{c}2(6) \\
11(31)^{*}\end{array}$ & $\begin{array}{l}10(34) \\
12(39)\end{array}$ & $\begin{array}{l}12(27) \\
16(35)\end{array}$ & $\begin{array}{r}8(20) \\
18(42)\end{array}$ \\
\hline Asthma medication last 12 months & $\begin{array}{l}\text { Control } \\
\text { Preterm }\end{array}$ & $\begin{array}{l}1(3) \\
5(14)\end{array}$ & $\begin{array}{l}1(3) \\
7(23)\end{array}$ & $\begin{array}{l}1(2) \\
7(16)\end{array}$ & $\begin{array}{l}3(8) \\
5(12)\end{array}$ \\
\hline Current asthmał & $\begin{array}{l}\text { Control } \\
\text { Preterm }\end{array}$ & $\begin{array}{c}1(3) \\
10(29)^{* *}\end{array}$ & $\begin{array}{l}5(17) \\
6(19)\end{array}$ & $\begin{array}{l}3(7) \\
8(17)\end{array}$ & $\begin{array}{l}3(8) \\
8(19)\end{array}$ \\
\hline
\end{tabular}


follow-up in 2001-2002 (figure 1). Neonatal mortality was $39 \%$ in the first inclusion period (1982-1985) and 27\% in the second $(1991-1992)(\mathrm{p}=0.157)$. Of the 86 survivors, $81(94 \%)$ participated at the first follow-up visit, 83 (97\%) participated on at least one visit and $74(86 \%)$ attended both (figure 1). Seven $(8 \%)$ of the 83 participants were included based on the birth weight criterion $\leq 1000 \mathrm{~g}$ alone, five in the 1982-1985 cohort (mean gestational age 30 weeks) and two in the 1991-1992 cohort (gestational age 30 and 31 weeks). All but two subjects were Caucasians. Two subjects in the 1982-1985 cohort had spastic tetraplegic cerebral palsy and scoliotic thorax restriction, one of whom had corrective surgery between the two examinations.

One term-born control was invited in 2001-2002 for each of the 81 preterm-born index subjects and 61 (75\%) of those primarily invited responded positively. Another 27 term-born subjects had to be approached to recruit a complete 1:1 individually matched control cohort. Fourteen (17\%) of these control subjects declined to participate in 2008-2009.

\section{Perinatal characteristics}

Subjects with neonatal BPD tended to be more immature and of lower birth weight and were more likely to have been treated with postnatal corticosteroids and with exogenous surfactant (in 1991-1992) (table 2). Significant changes from 1982-1985 to 1991-1992 were fewer ventilator days and more use of antenatal steroids in the mild BPD group, and lower gestational age and more use of postnatal steroids in the moderate/severe BPD group.

\section{Age, height and weight}

The results are presented as $\mathrm{z}$ scores in table 3 and raw data in online supplementary table $3 \mathrm{E}$. Preterm and term-born subjects were of similar mean (SD) age at the first and second follow-up examination (17.6 (1.2) vs 17.8 (1.2) years and $24.7(1.2)$ vs 25.1 (1.2) years, respectively, for the 1982-1985 cohort and $10.4(0.4)$ vs $10.6(0.4)$ years and $17.7(0.4)$ vs $17.9(0.5)$ years for the 1991-1992 birth cohort). Growth patterns between the first and second assessments did not differ between the three subgroups-that is, subjects born preterm with and without neonatal BPD and those born at term showed similar growth trajectories.

\section{Lung function}

The results are presented as $\mathrm{z}$ scores in table 4 and figure 2 and as percentage predicted in online supplementary table 4E. Satisfactory and reproducible flow-volume loops were obtained from all participants. Values reflecting airflow were significantly lower in subjects born preterm than at term over the complete study period. For most variables, deficits were more marked following neonatal BPD.

For subjects born in 1991-1992, the $\mathrm{z}$ scores for all spirometric variables were largely similar at 10 and 18 years of age within each of the four subgroups (EP-born subjects with no, mild or moderate/severe BPD and term-born control subjects).

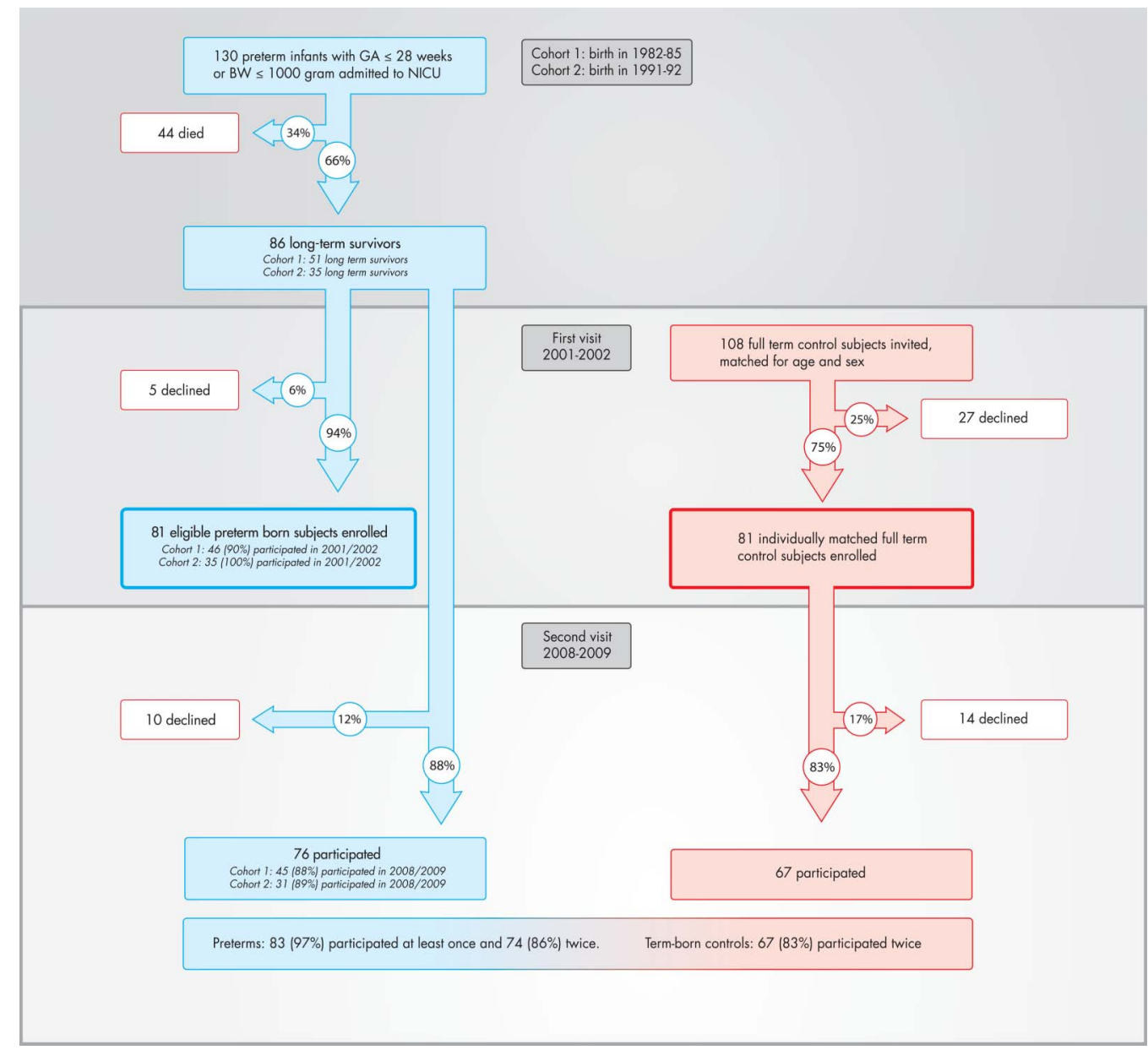

Figure 1 Recruitment process of the study. Two subjects participated in 2008/2009 but not in 2001/2002. BW, birth weight; GA, gestational age. 
Table 2 Perinatal data for 83 subjects born extremely preterm (EP) with and without neonatal BPD and 81 control subjects born at term

\begin{tabular}{|c|c|c|}
\hline & 1991-1992 Cohort & 1982-1985 Cohort \\
\hline \multicolumn{3}{|l|}{ Subjects, n (\%) } \\
\hline Control & 35 & 46 \\
\hline All EP & 35 & $48+$ \\
\hline EP non-BPD & $9(26)$ & $11(23)$ \\
\hline EP mild BPD & $14(40)$ & $24(50)$ \\
\hline $\mathrm{EP} \mathrm{m} / \mathrm{s} \mathrm{BPD}$ & $12(34)$ & $13(27)$ \\
\hline \multicolumn{3}{|c|}{ Female gender, $\mathrm{n}(\%)$} \\
\hline Control & $22(63)$ & $21(46)$ \\
\hline All EP & $22(63)$ & $21(44)$ \\
\hline EP non-BPD & $7(78)$ & $5(45)$ \\
\hline EP mild BPD & $10(71)$ & $11(46)$ \\
\hline $\mathrm{EP} \mathrm{m} / \mathrm{s} \mathrm{BPD}$ & $5(42)$ & $5(38)$ \\
\hline \multicolumn{3}{|c|}{ Birth weight (g), mean (range) } \\
\hline Control & $3564(3010-4000)$ & $3441(3000-4000)$ \\
\hline All EP & $933(570-1400)$ & $1012(580-1480)$ \\
\hline EP non-BPD & $1053(930-1400)$ & $1151(960-1480)$ \\
\hline EP mild BPD & $927(620-1370)$ & $1013(580-1340)$ \\
\hline $\mathrm{EP} \mathrm{m} / \mathrm{s} \mathrm{BPD}$ & $851(570-1200)$ & $892(670-1080)^{* *}$ \\
\hline \multicolumn{3}{|c|}{ Gestational age (weeks), mean (range) } \\
\hline All EP & $26.9(23-31)$ & $27.3(23-32)$ \\
\hline EP non-BPD & $28.3(26-31)$ & $28.5(27-32)$ \\
\hline EP mild BPD & $26.5(24-28)$ & $27.0(23-28)$ \\
\hline $\mathrm{EP} \mathrm{m} / \mathrm{s} \mathrm{BPD}{ }^{*}$ & $25.8(23-28)^{*}$ & $27.2(26-30)$ \\
\hline \multicolumn{3}{|c|}{ Gestational age at room air (weeks), median (range) } \\
\hline All EP & $34.0(28-50)$ & $34.0(28-63)$ \\
\hline EP non-BPD & $29.0(28-31)$ & $30.0(28-34)$ \\
\hline EP mild BPD & $33.5(30-35)$ & $33.0(31-35)$ \\
\hline $\mathrm{EP} \mathrm{m} / \mathrm{s} \mathrm{BPD}$ & $37.5(36-50)^{* * *}$ & $37.0(36-63)^{* * *}$ \\
\hline \multicolumn{3}{|c|}{ Postnatal days with oxygen treatment, median (range) } \\
\hline All EP & $49.0(2-180)$ & $42.0(1-257)$ \\
\hline EP non-BPD & $2.0(2-26)$ & $11.0(1-25)$ \\
\hline EP mild BPD & $45.5(28-70)$ & $41.0(28-71)$ \\
\hline $\mathrm{EP} \mathrm{m} / \mathrm{s} \mathrm{BPD}$ & $91.5(61-180)^{* * *}$ & $70.0(44-257)^{* * *}$ \\
\hline \multicolumn{3}{|c|}{ Ventilator days, median (range) } \\
\hline All EP & $4.0(0-54.5)$ & $8.0(0-54.0)$ \\
\hline EP non-BPD & $0.5(0-1.7)$ & $0.3(0-4.8)$ \\
\hline EP mild BPD* & $3.0(0-40.0)$ & $8.6(0.8-35)$ \\
\hline $\mathrm{EP} \mathrm{m} / \mathrm{s} \mathrm{BPD}$ & $12.7(1.7-54.5)^{* *}$ & $25.2(0.7-54.0)^{* *}$ \\
\hline \multicolumn{3}{|c|}{ Antenatal steroids, $\mathrm{n}(\%)$} \\
\hline All EP & $15 / 34(44)$ & $16 / 47(34)$ \\
\hline EP non-BPD & $3(33)$ & $5(45)$ \\
\hline EP mild BPD* & $8(57)$ & $5 / 23(22)$ \\
\hline EP m/s BPD & $4 / 11(36)$ & $6(46)$ \\
\hline \multicolumn{3}{|l|}{ Surfactant, n (\%) } \\
\hline All EP & $17(49)$ & - \\
\hline EP non-BPD & $1(11)$ & - \\
\hline EP mild BPD & $6(43)$ & - \\
\hline $\mathrm{EP} \mathrm{m} / \mathrm{s} \mathrm{BPD}$ & $10(83)^{* *}$ & - \\
\hline
\end{tabular}

Continued

There were no significant differences between the four groups regarding the pattern of lung function development over the study period (tests of interaction).

For subjects born in 1982-1985, the $\mathrm{z}$ scores for $\mathrm{FEV}_{1}$ and FVC were largely similar at 18 and 25 years of age while the z-scores for $\mathrm{FEV}_{1} / \mathrm{FVC}$ and for $\mathrm{FEF}_{25-75}$ tended to be lower at 25 years. There were no significant group differences regarding
Table 2 Continued

\begin{tabular}{|c|c|c|}
\hline & 1991-1992 Cohort & 1982-1985 Cohort \\
\hline \multicolumn{3}{|c|}{ Postnatal steroids, n (\%) } \\
\hline All EP & 10 (29) & 4/47 (9) \\
\hline EP non-BPD & 0 & 0) \\
\hline EP mild BPD & $2(14)$ & $1 / 23(4)$ \\
\hline $\mathrm{EP} \mathrm{m} / \mathrm{s} \mathrm{BPD}^{*}$ & $8(67)^{\star *}$ & $3(23)$ \\
\hline \multicolumn{3}{|c|}{$\begin{array}{l}\text { tComplete neonatal data available for } 47 / 48 \text { preterm-born subjects in the older } \\
\text { cohort. } \\
\text { Group comparisons were performed with the Student } t \text { test (normal distribution), } \\
\text { Mann-Whitney U test (asymmetrical continuous distribution) or Pearson exact } \chi^{2} \text { test } \\
\text { (categorical data) and results expressed as }{ }^{*} p<0.05,{ }^{* *} p<0.01,{ }^{* *} p<0.001 \text { (column } \\
1 \text { regarding cohort differences and columns } 2 \text { and } 3 \text { regarding within-cohort } \\
\text { subgroup differences in BPD). } \\
\text { BPD, bronchopulmonary dysplasia; EP, subjects born extreme preterm (ie, gestational } \\
\text { age } \leq 28 \text { weeks or birth weight } \leq 1000 \mathrm{~g} \text { ); } \mathrm{m} / \mathrm{s} B P D \text {, moderate/severe BPD (ie, oxygen } \\
\text { supplement at gestational age } 36 \text { weeks); mild BPD, oxygen supplement at } 28 \\
\text { postnatal days. }\end{array}$} \\
\hline
\end{tabular}

the pattern of lung function development over the study period (tests of interaction).

Both birth cohorts had lung function studies at 18 years of age, although approximately 7 years apart, and the findings were principally similar except that $\mathrm{z}$-FVC was lower and $\mathrm{z}-\mathrm{FEV}_{1} / \mathrm{FVC}$ was higher in the moderate/severe BPD group of the 1982-1985 cohort (see online supplement for details).

For each of the study groups there was a close correlation between $\mathrm{z}$ scores for $\mathrm{FEV}_{1}$ and $\mathrm{FEF}_{25-75}$ obtained at the first and second visit, and the correlations were similar for the preterm- and term-born cohorts $\left(\mathrm{R}^{2}=0.64-0.83\right.$, figure 3$)$.

\section{Lung function related to background}

Detailed statistical results are listed in the online supplement. Regressing $\mathrm{z}-\mathrm{FEV}_{1}$ on the background variables listed in table 1 revealed significant effects from asthma and use of asthma medication in preterm-born subjects in the 1991-1992 cohort, both reducing $\mathrm{z}-\mathrm{FEV}_{1}$ in the range of $0.5-0.6$. In the 1982-1985 cohort, this association could not be observed; however, in the control group maternal smoking contributed negatively in a final model containing several explanatory variables. Apart from the effects from BPD (table 4 and online supplementary table $4 \mathrm{E})$, the only neonatal variable with significant long-term influence on $\mathrm{FEV}_{1}$ was postnatal treatment with corticosteroids in the 1991-1992 cohort, reducing $\mathrm{z}$ scores with 0.6. None of the included variables influenced the interaction terms - that is, neither neonatal nor background characteristics influenced tracking of $\mathrm{z}-\mathrm{FEV}_{1}$ differently in the various subgroups of the study.

\section{DISCUSSION}

This is the first controlled population-based study describing the development of lung function from mid-childhood through puberty and from late adolescence into adult life for EP-born subjects. Airway obstruction was observed throughout the complete study period and was most pronounced for those with neonatal BPD. However, lung function trajectories did not differ between the preterm- and term-born groups or between those born preterm with and without neonatal BPD, suggesting a parallel development throughout the study period.

The major strengths of this study are the population-based design, long follow-up period and nearly complete attendance. Perinatal data for EP-born participants were prospectively and systematically recorded and tabulated while subjects were still in 
Table 3 Height and weight expressed as z scores from 10 to 25 years of age for 83 subjects born EP with and without neonatal BPD and 81 term-born control subjects

\begin{tabular}{|c|c|c|c|c|c|c|}
\hline \multirow{3}{*}{$\begin{array}{l}\text { Examination } \\
\text { Mean (SD age (years) }\end{array}$} & \multicolumn{3}{|c|}{$\begin{array}{l}1991-1992 \text { cohort } \\
\text { Development from childhood to adolescence }\end{array}$} & \multicolumn{3}{|c|}{$\begin{array}{l}1982-1985 \text { cohort } \\
\text { Development from adolescence to adulthood }\end{array}$} \\
\hline & $\begin{array}{l}\text { First } \\
10.5(0.4)\end{array}$ & $\begin{array}{l}\text { Second } \\
17.8(0.4)\end{array}$ & & $\begin{array}{l}\text { First } \\
17.7(1.2)\end{array}$ & $\begin{array}{l}\text { Second } \\
24.9(1.2)\end{array}$ & \\
\hline & z Score & z Score & Difference $\Delta Z$ & z Score & z Score & Difference $\Delta \mathrm{Z}$ \\
\hline \multicolumn{7}{|l|}{ Height, $\mathrm{cm}$; mean $(95 \% \mathrm{Cl})$} \\
\hline Control & $0.03(-0.32$ to 0.38$)$ & $-0.15(-0.50$ to 0.20$)$ & $-0.18(-0.41$ to 0.05$)$ & $-0.14(-0.41$ to 0.13$)$ & $-0.22(-0.50$ to 0.06$)$ & $-0.08(-0.15$ to -0.004$)$ \\
\hline EP non-BPD & $-0.32(-1.02$ to 0.37$)$ & $-0.91(-1.61$ to -0.21$)$ & $-0.58(-1.05$ to -0.11$)$ & $-0.24(-0.78$ to 0.31$)$ & $-0.29(-0.86$ to 0.28$)$ & $-0.05(-0.20$ to 0.09$)$ \\
\hline EP mild BPD & $-0.64(-1.20$ to -0.08$)$ & $-0.69(-1.24$ to -0.14$)$ & $0.05(-0.41$ to 0.30$)$ & $-0.75(-1.12$ to -0.38$)$ & $-0.96(-1.35$ to -0.57$)$ & $-0.21(-0.31$ to -0.11$)$ \\
\hline $\mathrm{EP} \mathrm{m} / \mathrm{s} \mathrm{BPD}$ & $-0.48(-1.08$ to -0.12$)$ & $-0.69(-1.27$ to -0.11$)$ & $-0.21(-0.57$ to 0.15$)$ & $-0.94(-1.44$ to -0.44$)$ & $-0.99(-1.52$ to -0.46$)$ & $-0.050(-0.19$ to 0.09$)$ \\
\hline Control vs EP no BPD† & $-0.35(-1.13$ to 0.43$)$ & $-0.76(-1.54$ to 0.03$)$ & & $-0.10(-0.70$ to 0.51$)$ & $-0.07(-0.71$ to 0.56$)$ & \\
\hline Control vs EP mild BPD $†$ & $-0.67(-1.33$ to -0.01$)$ & $-0.54(-1.20$ to 0.11$)$ & $\mathrm{p}=0.346$ & $-0.61(-1.07$ to -0.16$)$ & $-0.74(-1.22$ to -0.26$)$ & $\mathrm{p}=0.128$ \\
\hline Control vs EP m/s BPD $\dagger$ & $-0.51(-1.21$ to 0.19$)$ & $-0.54(-1.22$ to 0.14$)$ & & $-0.80(-1.37$ to -0.23$)$ & $-0.77(-1.37$ to -0.18$)$ & \\
\hline \multicolumn{7}{|l|}{ Weight, kg; mean $(95 \%$ Cl) } \\
\hline Control & $0.17(-0.21$ to 0.56$)$ & $0.38(-0.16$ to 0.92$)$ & $0.21(-0.15$ to 0.56$)$ & $0.14(-0.32$ to 0.61$)$ & $0.56(0.13$ to 1.00$)$ & $0.42(0.05$ to 0.79$)$ \\
\hline EP non-BPD & $0.14(-0.63$ to 0.90$)$ & $0.91(-0.16$ to 1.98$)$ & 0.77 (0.06 to 1.49 ) & $0.63(-0.34$ to 1.61$)$ & 1.45 (0.59 to 2.30$)$ & 0.81 (0.07 to 1.56$)$ \\
\hline EP mild BPD & $-0.75(-1.36$ to -0.13$)$ & $-0.32(-1.16$ to 0.52$)$ & $0.42(-0.12$ to 0.97$)$ & $-0.80(-1.45$ to -0.14$)$ & $0.17(-0.42$ to 0.76$)$ & 0.97 (0.46 to 1.48 ) \\
\hline $\mathrm{EP} \mathrm{m} / \mathrm{s} \mathrm{BPD}$ & $-0.61(-1.27$ to 0.06$)$ & $-0.12(-1.00$ to 0.76$)$ & $0.50(-0.05$ to 1.03$)$ & $-0.96(-1.85$ to -0.06$)$ & $-0.28(-1.08$ to 0.52$)$ & $0.67(-0.03$ to 1.38$)$ \\
\hline Control vs EP no BPD† & $-0.04(-0.90$ to 0.82$)$ & $0.53(-0.67$ to 1.72$)$ & & $0.49(-0.59$ to 1.57$)$ & $0.88(-0.08$ to 1.84$)$ & \\
\hline Control vs EP mild BPD $†$ & $-0.92(-1.65$ to -0.19$)$ & $-0.70(-1.70$ to 0.29$)$ & $\mathrm{p}=0.506$ & $-0.94(-1.74$ to -0.14$)$ & $-0.39(-1.12$ to 0.34$)$ & $\mathrm{p}=0.360$ \\
\hline Control vs EP m/s BPD† & $-0.78(-1.55$, to -0.01$)$ & $-0.50(-1.53$ to 0.54$)$ & & $-1.10(-2.11$ to -0.09$)$ & $-0.84(-1.75$ to 0.07$)$ & \\
\hline
\end{tabular}

Figures are group mean z scores with $95 \% \mathrm{Cls}$ or group mean differences with $95 \% \mathrm{Cl}$, except for age (mean value with SDs). p Values assess group differences with respect to development from the first to the second examination (mixed linear model of SPSS, tests of group vs examination interaction). $\Delta \mathrm{Z}$ denotes mean change in z score from first to second examination.

TDenotes differences between the control groups and the respective EP BPD subgroups.

BPD, bronchopulmonary dysplasia; EP, subjects born extreme preterm (ie, gestational age $\leq 28$ weeks or birth weight $\leq 1000 \mathrm{~g}$ ); m/s BPD, moderate/severe BPD (ie, oxygen supplement at gestational age 36 weeks); mild BPD, oxygen supplement at 28 postnatal days. 
Table 4 Spirometric lung function data expressed as z scores from 10 to 25 years of age for 83 subjects born EP with and without neonatal BPD and 81 term-born control subjects

\begin{tabular}{|c|c|c|c|c|c|c|}
\hline \multirow{3}{*}{$\begin{array}{l}\text { Examination } \\
\text { Mean (SD) age (years) }\end{array}$} & \multicolumn{3}{|c|}{$\begin{array}{l}\text { 1991-1992 cohort } \\
\text { Development from childhood to adolescence }\end{array}$} & \multicolumn{3}{|c|}{$\begin{array}{l}\text { 1982-1985 cohort } \\
\text { Development from adolescence to adulthood }\end{array}$} \\
\hline & $\begin{array}{l}\text { First } \\
10.5(0.4)\end{array}$ & $\begin{array}{l}\text { Second } \\
17.8(0.4)\end{array}$ & & $\begin{array}{l}\text { First } \\
17.7(1.2)\end{array}$ & $\begin{array}{l}\text { Second } \\
24.9(1.2)\end{array}$ & \\
\hline & z Score & z Score & Difference $\Delta Z$ & z Score & z Score & Difference $\Delta \mathbf{Z}$ \\
\hline \multicolumn{7}{|l|}{$\mathrm{FEV}_{1}$ mean $(95 \% \mathrm{Cl})$} \\
\hline Control & $-0.054(-0.31$ to 0.20$)$ & $-0.028(-0.34$ to 0.29$)$ & $0.026(-0.19$ to 0.24$)$ & $0.22(-0.16$ to 0.60$)$ & $-0.009(-0.37$ to 0.35$)$ & $-0.23(-0.41$ to -0.04$)$ \\
\hline EP non-BPD & $-0.25(-0.75$ to 0.24$)$ & $-0.12(-0.74$ to 0.50$)$ & $0.14(-0.29$ to 0.56$)$ & $-0.41(-1.19$ to 0.38$)$ & $-0.52(-1.25$ to 0.20$)$ & $-0.12(-0.48$ to 0.25$)$ \\
\hline EP mild BPD & $-0.75(-1.15$ to -0.35$)$ & $-0.63(-1.12$ to -0.14$)$ & $0.12(-0.20$ to 0.45$)$ & $-1.24(-1.76$ to -0.71$)$ & $-1.03(-1.53$ to -0.53$)$ & $0.21(-0.04$ to 0.45$)$ \\
\hline $\mathrm{EP} \mathrm{m} / \mathrm{s} \mathrm{BPD}$ & $-1.41(-1.84$ to -0.98$)$ & $-1.29(-1.80$ to -0.78$)$ & $0.12(-0.21$ to 0.44$)$ & $-1.36(-2.08$ to -0.64$)$ & $-1.36(-2.03$ to -0.68$)$ & $0.001(-0.35$ to 0.35$)$ \\
\hline Control vs EP no BPD $†$ & $0.20(-0.35$ to 0.76$)$ & $0.09(-0.61$ to 0.78$)$ & & $0.62(-0.25$ to 1.50$)$ & $0.52(-0.30$ to 1.33$)$ & \\
\hline Control vs EP mild BPD† & $0.70(0.23$ to 1.17$)$ & $0.60(0.02$ to 1.17$)$ & $\mathrm{p}=0.929$ & $1.46(0.81$ to 2.10$)$ & 1.02 (0.41 to 1.64$)$ & $\mathrm{p}=0.050$ \\
\hline Control vs EP m/s BPD $\dagger$ & 1.35 (0.86 to 1.85 ) & 1.26 (0.66 to 1.86$)$ & & 1.58 (0.76 to 2.39$)$ & 1.35 (0.58 to 2.11$)$ & \\
\hline \multicolumn{7}{|l|}{ FVC mean $(95 \% \mathrm{Cl})$} \\
\hline Control & $-0.12(-0.38$ to 0.14$)$ & -0.072 ( -0.38 to 0.24$)$ & $0.05(-0.18$ to 0.27$)$ & $-0.16(-0.58$ to 0.27$)$ & 0.005 ( -0.40 to 0.41$)$ & $0.16(-0.05$ to 0.37$)$ \\
\hline EP non-BPD & $-0.38(-0.89$ to 0.14$)$ & $-0.047(-0.66$ to 0.57$)$ & $0.33(-0.13$ to 0.79$)$ & $-0.043(-0.92$ to 0.84$)$ & $0.29(-0.52$ to 1.10$)$ & $0.33(-0.13$ to 0.79$)$ \\
\hline EP mild BPD & $-0.63(-1.04$ to -0.22$)$ & $-0.59(-1.08$ to -0.11$)$ & $0.03(-0.32$ to 0.38$)$ & $-1.30(-1.89$ to -0.71$)$ & $-0.66(-1.21$ to -0.10$)$ & 0.64 (0.37 to 0.92$)$ \\
\hline $\mathrm{EP} \mathrm{m} / \mathrm{s} \mathrm{BPD}$ & $-0.61(-1.05$ to -0.16$)$ & $-0.15(-0.66$ to 0.35$)$ & $0.46(0.10,0.81)$ & $-1.07(-1.87$ to -0.25$)$ & $-0.68(-1.43$ to 0.072$)$ & $0.38(-0.01$ to 0.77$)$ \\
\hline Control vs EP no BPD $†$ & $0.26(-0.32$ to 0.83$)$ & $-0.03(-0.72$ to 0.66$)$ & & $-0.11(-1.09$ to 0.87$)$ & $-0.28(-1.19$ to 0.62$)$ & \\
\hline Control vs EP mild BPD† & $0.51(0.02$ to 0.99$)$ & $0.52(-0.05$ to 1.10$)$ & $p=0.190$ & $1.14(0.42$ to 1.87$)$ & $0.66(-0.02$ to 1.35$)$ & $\mathrm{p}=0.058$ \\
\hline Control vs EP m/s BPD $\dagger$ & $0.49(-0.02$ to 1.00$)$ & $0.08(-0.51$ to 0.67$)$ & & $0.90(-0.01$ to 1.82$)$ & $0.68(-0.17$ to 1.54$)$ & \\
\hline \multicolumn{7}{|l|}{$\mathrm{FEV}_{1} / \mathrm{FVC}$ mean $(95 \% \mathrm{Cl})$} \\
\hline Control & $0.009(-0.32$ to 0.33$)$ & 0.018 (-0.37 to 0.41$)$ & 0.01 ( to 0.24 to 0.26 ) & 0.53 (0.21 to 0.85$)$ & $-0.018(-0.30$ to 0.27$)$ & $-0.55(-0.77$ to -0.32$)$ \\
\hline EP non-BPD & $0.22(-0.42$ to 0.86$)$ & $-0.18(-0.96$ to 0.59$)$ & $-0.40(-0.90$ to 0.10$)$ & $-0.55(-1.21$ to 0.12$)$ & $-1.13(-1.69$ to -0.57$)$ & $-0.59(-1.04$ to -0.31$)$ \\
\hline EP mild BPD & $-0.18(-0.70$ to 0.33$)$ & -0.031 ( -0.64 to 0.58$)$ & $0.15(-0.23$ to 0.54$)$ & $0.037(-0.40$ to 0.48$)$ & $-0.62(-1.01$ to -0.24$)$ & $-0.66(-0.96$ to -0.35$)$ \\
\hline $\mathrm{EP} \mathrm{m} / \mathrm{s} \mathrm{BPD}$ & $-1.34(-1.89$ to -0.78$)$ & $-1.44(-2.08$ to -0.79$)$ & $-0.10(-0.48$ to 0.29$)$ & $-0.42(-1.04$ to 0.19$)$ & $-0.78(-1.31$ to -0.25$)$ & $-0.35(-0.79$ to 0.07$)$ \\
\hline Control vs EP no BPD $†$ & $-0.21(-0.93$ to 0.51$)$ & 0.20 (-0.67 to 1.07$)$ & & $1.08(0.34,1.81)$ & 1.12 (0.49 to 1.74$)$ & \\
\hline Control vs EP mild BPD† & $0.19(-0.42$ to 0.80$)$ & $0.05(-0.68$ to 0.77$)$ & $\mathrm{p}=0.354$ & $0.50(-0.05$ to 1.04$)$ & $0.60(0.12$ to 1.09$)$ & $\mathrm{p}=0.721$ \\
\hline Control vs EP m/s BPD† & 1.35 (0.70 to 1.99$)$ & 1.45 (0.70 to 2.21$)$ & & 0.95 (0.27 to 1.64$)$ & 0.80 (0.16 to 1.36$)$ & \\
\hline \multicolumn{7}{|l|}{$\mathrm{FEF}_{25-75}$ mean $(95 \% \mathrm{Cl})$} \\
\hline Control & -0.16 ( -0.46 to 0.14$)$ & $-0.12(-0.46$ to 0.23$)$ & $0.04(-0.17$ to 0.26$)$ & 0.47 (0.18 to 0.77$)$ & 0.012 (-0.30 to 0.33$)$ & $-0.46(-0.64$ to -0.28$)$ \\
\hline EP non-BPD & $-0.36(-0.95$ to 0.23$)$ & $-0.25(-0.94$ to 0.44$)$ & $0.11(-0.31$ to 0.53$)$ & $-0.63(-1.25$ to -0.01$)$ & $-1.19(-1.83$ to -0.55$)$ & $-0.56(-0.93$ to -0.19$)$ \\
\hline EP mild BPD & $-0.84(-1.31$ to -0.37$)$ & $-0.40(-0.94$ to 0.14$)$ & $0.44(0.12$ to 0.76$)$ & $-0.76(-1.17$ to -0.34$)$ & $-1.07(-1.50$ to -0.64$)$ & $-0.31(-0.55$ to -0.07$)$ \\
\hline $\mathrm{EP} \mathrm{m} / \mathrm{s} \mathrm{BPD}$ & $-1.84(-2.35$ to -1.33$)$ & $-1.67(-2.25$ to -1.10$)$ & $0.17(-0.15$ to 0.49$)$ & $-1.19(-1.76$ to -0.62$)$ & $-1.34(-1.93$ to -0.76$)$ & $-0.16(-0.49$ to 0.18$)$ \\
\hline Control vs EP no BPD $†$ & $0.19(-0.47$ to 0.85$)$ & $0.13(-0.64$ to 0.90$)$ & & 1.10 (0.41 to 1.79$)$ & $1.20(0.49$ to 1.91$)$ & \\
\hline Control vs EP mild BPD† & 0.68 (0.12 to 1.24$)$ & $0.28(-0.36$ to 0.93$)$ & $p=0.244$ & 1.23 (0.72 to 1.74$)$ & 1.08 (0.55 to 1.61$)$ & $\mathrm{p}=0.275$ \\
\hline Control vs EP m/s BPD† & 1.68 (1.09 to 2.27$)$ & 1.56 (0.89 to 2.23$)$ & & 1.66 (1.02 to 2.31$)$ & 1.35 (0.69 to 2.02$)$ & \\
\hline
\end{tabular}

Figures are group mean z scores with $95 \%$ Cls or group mean differences with $95 \% \mathrm{Cl}$, except for age (mean value with SDs). p Values assess differences between the three subgroups with respect to development from the first to the second examination (mixed linear model of SPSS, tests of group vs examination interaction). $\Delta Z$ denotes mean change in z score from first to second examination.

†Denotes differences between the control groups and the respective BPD subgroups.

$\mathrm{BPD}$, bronchopulmonary dysplasia; EP, subjects born extreme preterm (ie, gestational age $\leq 28$ weeks or birth weight $\leq 1000 \mathrm{~g}$ ); FEF $25-75$, forced expiratory flow at $25-75 \%$ of FVC; FEV ${ }_{1}$, forced expiratory volume in $1 \mathrm{~s}$; FVC, forced vital capacity; $\mathrm{m} / \mathrm{s}$ BPD, moderate/severe BPD (ie, oxygen supplement at gestational age 36 weeks); mild BPD, oxygen supplement at 28 postnatal days; z Score, (observed value - expected value)/(SE of the expected value), calculated with the all-age reference equation. ${ }^{17}$ 
the NICU. Subjects were retrospectively included in 2001, but the organisation of medical care in the region and identical algorithms for determination of gestational age at birth ensured that recruitment would have been the same if performed prospectively. The control groups were the same throughout the study period and were recruited according to a strict algorithm based on the 'next-born subject' principle. This approach minimised the risk of selection bias inherent in all open forms of recruitment, particularly as most of those first invited consented. Finally, and contrary to some previous studies, ${ }^{10}{ }^{11}$ the all-age reference equation provided by Stanojevic et $a l^{17}$ allowed for uniform handling of data from childhood to adulthood. ${ }^{19}$ The equation fitted the control population well with two exceptions: for $\mathrm{FEF}_{25-75}$ and $\mathrm{FEV}_{1} / \mathrm{FVC}$ measured at 18 years of age in the 1982-1985 cohort, the 95\% CIs did not include zero. The prime objective of this study was to include all EP-born neonates (ie, at gestational age $\leq 28$ weeks). However, early ultrasound scans were not routinely performed in the early 1980 s and a weight criterion was introduced due to the possible uncertainty of setting delivery dates by menstrual data alone. Splitting the dataset by BPD facilitated focus on those with the most complex neonatal history and possibly most at risk for later chronic obstructive pulmonary disease (COPD), but also led to fewer subjects in each subgroup, complicating statistical conclusions. Instead of reporting p values we have generally used 95\% CIs to address uncertainties for estimated mean values, except for interaction terms used to address developmental differences.

The majority of young people have large ventilatory reserves, even when performing high intensity physical activities. Moderate deficits and normal age-related declines in airflow capacities throughout adulthood are therefore generally well tolerated. ${ }^{12}$ However, severe airway obstruction has been reported in some young survivors of BPD. ${ }^{11}{ }^{13} 20-24$ The lifelong implications from these findings depend on subsequent developmental patterns, and further declines may well mean that thresholds for respiratory symptoms and COPD are already reached in middle age in some of these individuals. A major finding of the present study was that $\mathrm{FEV}_{1}$ was remarkably stable from age 10 to 18 and from 18 to 25 in all subgroups, and also for those with the most severe deficits in the moderate/severe BPD group. In the latter subgroup the mean $\mathrm{FEV}_{1}$ percentage predicted barely exceeded $80 \%$, which is considered a cut-off level required for a diagnosis of COPD. Viewed in this context, a further decline of $5 \%$, or approximately $0.5 \mathrm{z}$ scores, could implicate a long-term clinical bearing. We know from other studies that age-related lung function decline differs between population subgroups, and that factors such as cigarette smoking, wheeze and asthma influence development. Conceivably, these and also neonatal factors other than BPD may have an added negative effect on lung function development after preterm birth. The size of our dataset precludes firm statements, but we were able to single out asthma and postnatal treatment with corticosteroids as such potential risk factors for reduced z-FEV 1 at age 18 in the 19911992 preterm-born cohort. Larger longitudinal studies across decades are necessary to unravel these issues and these are logistically demanding to carry out, illustrated by a paucity of studies and the high dropout rates in some of them. A complicating and relevant factor is that pubertal lung function development is difficult to modulate mathematically, as illustrated by Quanjer et al. ${ }^{19}$ Thus, to avoid being misled, high quality reference equations are critical and comparable subjects 'unexposed' to preterm birth should be studied in parallel.

Preterm infants born in the 1980s and 1990s were exposed to different neonatal treatment techniques, policies and algorithms, and standard NICU care improved during this period. In parallel, there was a trend towards increased survival particularly for the smallest infants, partly reflected also in our dataset. These changes open for cohort effects and alterations in outcomes that may be difficult to predict. Direct comparisons between subjects born preterm during these two periods should therefore be cautiously interpreted. Nevertheless, one may speculate that the observed cohort differences regarding FVC and $\mathrm{FEV}_{1} / \mathrm{FVC}$ may represent alterations reflecting a more restrictive lung function pattern of the 'old BPD' of the $1980 \mathrm{~s}$. Our main objective was, however, to address tracking of lung function - that is, to examine if the airway obstruction repeatedly reported for ex-preterm children is likely to persist to adulthood and thereby represent a potential precursor of COPD. One may argue that a similar development in groups born several years apart (and therefore exposed to different treatment regimens) and also in subgroups with relatively large variations with respect to lung function outcome do not weaken the notion that $\mathrm{FEV}_{1}$-also after preterm birth-is tracking from childhood to adulthood. Neither neonatal nor other background variables could be shown to influence the interaction terms used to compare the growth trajectories in the various subgroups. Thus, although lung function is reduced after EP birth, the rate of growth and development does not seem to differ from that of term-born peers. Interestingly, from 18 to 25 years of age there was a slight downward trend for the
Figure 2 Forced expiratory volume in $1 \mathrm{~s}\left(\mathrm{FEV}_{1}\right)$ in 83 preterm-born subjects, 25 with requirement for oxygen treatment at 36 weeks gestational age (bronchopulmonary dysplasia (BPD)) and 58 without (no BPD), and in 81 controls subjects born at term. The y axis represents $z$ scores for $F_{1} V_{1}$ (ie, the number of SDs the measurements are above or below the value predicted by the all-age reference equation). ${ }^{17}$ Dots represent group means and triangles/coloured areas are $95 \% \mathrm{Cls}$. Age in years on the $x$ axis is split at 18 as the dataset comes from two birth cohorts born in 1991-1992 (Teens) and 1982-1985 (Adults).

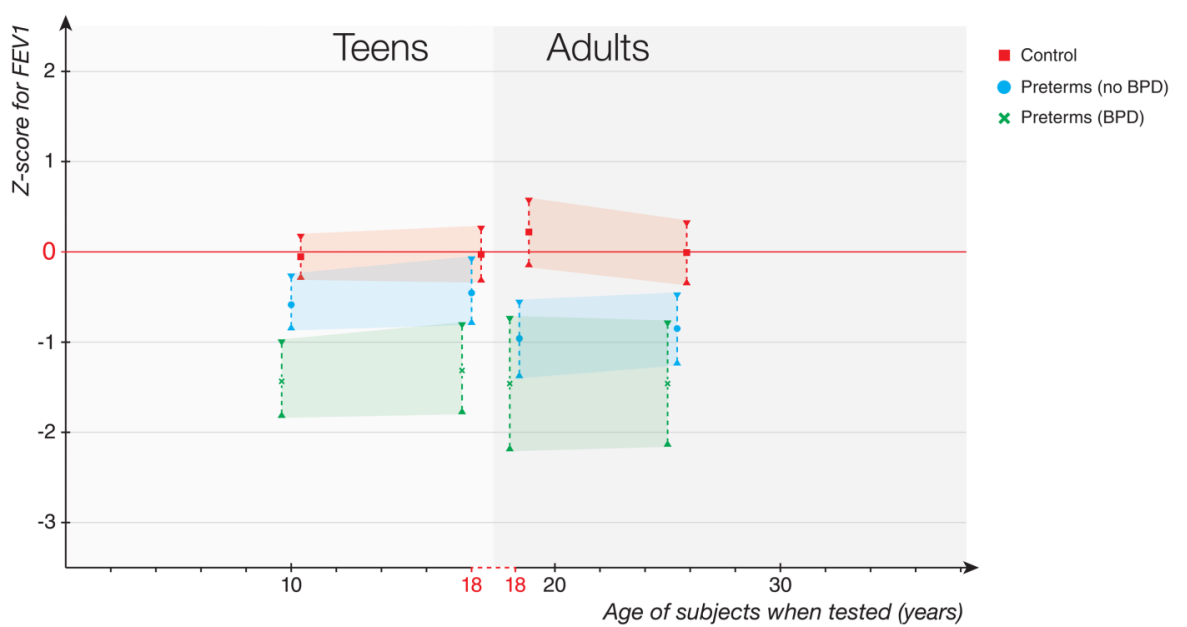



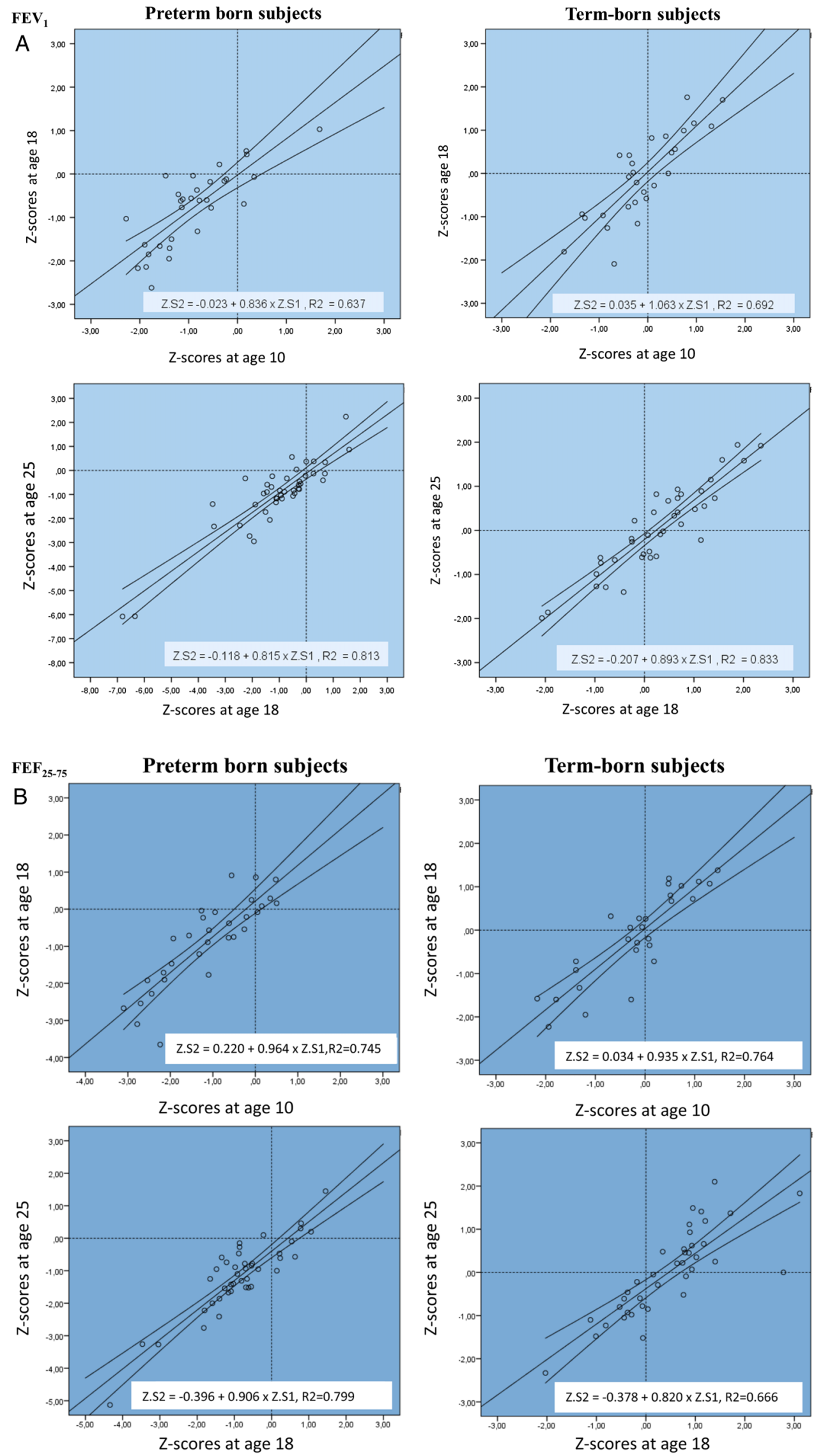

Figure 3 Scatterplots depicting $\mathrm{z}$ scores of $(\mathrm{A})$ forced expiratory volume in $1 \mathrm{~s}\left(\mathrm{FEV}_{1}\right)$ and $(\mathrm{B})$ forced mid-expiratory flow $\left(\mathrm{FEF}_{25-75}\right)$ in preterm- and term-born participants. Measured values were transformed to $z$ scores using the all-age reference equation. ${ }^{17}$ Results obtained at the younger age (S1) on the $x$ axis and at the older age (S2) on the $y$ axis. Full lines are regression lines with mean $95 \%$ Cls. Prediction equations and coefficients of determination $\left(R^{2}\right)$ are given for each variable and group. 
variables $\mathrm{FEV}_{1} / \mathrm{FVC}$ and $\mathrm{FEF}_{25-75}$ which affected all subgroups similarly, suggesting that an age-related small airway obstruction had possibly begun for all.

Few studies have investigated the longitudinal development of lung function after preterm birth. Two studies from the 1990s are difficult to interpret since they did not include term-born controls. ${ }^{25}{ }^{26}$ In a study from Italy, 17 subjects with BPD (oxygen therapy at 28 postnatal days) born at a mean gestational age of 28.1 weeks were examined at 2, 9 and 15 years of age. Compared with control subjects born at term, they had significantly lower $\mathrm{FEV}_{1}$ and $\mathrm{z}$ scores were basically stable throughout the study period. ${ }^{9} 2728$ In a cohort from London born at a mean gestational age of 31.5 weeks, airway obstruction was observed at 7-9 years of age but not at 21 years. ${ }^{10} 29$ The authors concluded that some catch-up development had occurred; however, only $20 \%$ of the original cohort participated at 21 years and different term-born control groups were recruited for the two visits. In Melbourne, a large cohort of subjects born with birth weight $<1500$ g were followed until 18 years of age. ${ }^{11} 3031$ Subjects with BPD (oxygen therapy at 28 postnatal days, $n=33$ ), but not those without BPD, had marked airway obstruction that tended to worsen from 8 to 18 years of age; however, developmental data for term-born control subjects were not detailed.

\section{CONCLUSIONS}

The present study suggests that EP-born subjects have significant airway obstruction which tracks from childhood through puberty to adulthood. Some decline in small airway dimensions may have begun at 25 years of age which is similar in pretermand term-born groups. We know that age-related decline in lung function varies between subjects ${ }^{12} 32$ and that cigarette smoking, childhood pneumonias, ${ }^{33}$ asthma ${ }^{34}$ and airway hyperresponsiveness $^{35}$ may accelerate this process. These traits and exposures are highly relevant for a large proportion of preterm-born individuals. $^{311}$ Thus, the present study certainly underlines the risk of premature onset of COPD in subsets of this group, substantiating proposals put forward in an editorial by Wohl in $1990 .^{36}$

Acknowledgements The authors thank Dr Petur Juliusson for help in converting measures of height and weight to $z$ scores using novel reference equations developed by his group.

Contributors All authors made a significant contribution to the conception and design or analysis and interpretation of data, drafting the article and/or revising it critically for important content and final approval of the version to be published. No person fulfilling these criteria has been omitted as an author. MV was responsible for writing the paper, planning and performing the current analyses, designing and performing the figures, literature search and took part in data collection. ODR participated in planning the study and performing the data collection, was the lung technician responsible for all the lung functions tests in the laboratory and participated in interpretation of the results and critical reading of the figures and manuscript. GEE participated in data analysis and interpretation, designing of figures, critical reading of figures, tables and manuscript and was the statistician of the study. TM was responsible for systematic data collection during the neonatal period and participated in planning and performing the current analyses, interpretation and writing the paper. TH was responsible for systematic data collection during childhood, adolescence and adulthood and was the main physician seeing all the study subjects in the laboratory and participated in planning and performing the current analyses, interpretation and writing the paper; he is the guarantor for the overall content.

Funding Major funding institutions: University of Bergen, Western Norway Regional Health Authority and Haukeland University Hospital. Minor support: Pediatric Lung Research Fund, Haukeland University Hospital.

\section{Competing interests None.}

Ethics approval The study was approved by the Regional Committee on Medical Research Ethics of the Western Norway Health Authority.

Patient consent Informed written consent was obtained from all participants and/or guardians.
Provenance and peer review Not commissioned; externally peer reviewed.

\section{REFERENCE}

1 Fanaroff AA, Hack M, Walsh MC. The NICHD neonatal research network: changes in practice and outcomes during the first 15 years. Semin Perinatol 2003;27:281-7.

2 Markestad T, Kaaresen PI, Ronnestad A, et al. Early death, morbidity, and need of treatment among extremely premature infants. Pediatrics 2005;115:1289-98.

3 Narang I. Review series: What goes around, comes around: childhood influences on later lung health? Long-term follow-up of infants with lung disease of prematurity. Chron Respir Dis 2010;7:259-69.

4 Baraldi E, Filippone M. Chronic lung disease after premature birth. N Eng/ J Med 2007;357:1946-55.

5 Coalson JJ. Pathology of bronchopulmonary dysplasia. Semin Perinatol 2006;30:179-84.

6 Northway WH Jr, Rosan RC, Porter DY. Pulmonary disease following respiratory therapy of hyaline-membrane disease. Bronchopulmonary dysplasia. N Engl J Med 1967;276:357-68.

7 Stoll BJ, Hansen $\mathrm{NI}$, Bell EF, et al. Neonatal outcomes of extremely preterm infants from the NICHD Neonatal Research Network. Pediatrics 2010;126:443-56.

8 Kobaly K, Schluchter M, Minich N, et al. Outcomes of extremely low birth weight $(<1 \mathrm{~kg})$ and extremely low gestational age ( $<28$ weeks) infants with bronchopulmonary dysplasia: effects of practice changes in 2000 to 2003. Pediatrics 2008;121:73-81.

9 Filippone $\mathrm{M}$, Bonetto $\mathrm{G}$, Cherubin $\mathrm{E}$, et al. Childhood course of lung function in survivors of bronchopulmonary dysplasia. JAMA 2009;302:1418-20.

10 Narang I, Rosenthal M, Cremonesini D, et al. Longitudinal evaluation of airway function 21 years after preterm birth. Am J Respir Crit Care Med 2008;178:74-80.

11 Doyle LW, Faber B, Callanan C, et al. Bronchopulmonary dysplasia in very low birth weight subjects and lung function in late adolescence. Pediatrics 2006:118:108-13.

12 Kerstjens HA, Rijcken B, Schouten JP, et al. Decline of FEV ${ }_{1}$ by age and smoking status: facts, figures, and fallacies. Thorax 1997;52:820-7.

13 Halvorsen T, Skadberg BT, Eide GE, et al. Better care of immature infants; has it influenced long-term pulmonary outcome? Acta Paediatr 2006;95:547-54.

14 The OSIRIS Collaborative Group. Early versus delayed neonatal administration of a synthetic surfactant: the judgment of OSIRIS (open study of infants at high risk of or with respiratory insufficiency-the role of surfactant). Lancet 1992;340:1363-9.

15 Jobe AH, Bancalari E. Bronchopulmonary dysplasia. Am J Respir Crit Care Med 2001;163:1723-9.

16 Quanjer PH, Tammeling GJ, Cotes JE, et al. Lung volumes and forced ventilatory flows. Report Working Party Standardization of Lung Function Tests, European Community for Steel and Coal. Official Statement of the European Respiratory Society. Eur Respir J Supp/ 1993;16:5-40.

17 Stanojevic S, Wade A, Stocks J, et al. Reference ranges for spirometry across all ages: a new approach. Am J Respir Crit Care Med 2008;177:253-60.

18 Davis CS. Statistical methods for the analysis of repeated measurements. Springer Verlag, 2002.

19 Quanjer PH, Hall GL, Stanojevic S, et al. Age- and height-based prediction bias in spirometry reference equations. Eur Respir J 2012;40:190-7.

20 Fawke J, Lum S, Kirkby J, et al. Lung function and respiratory symptoms at 11 years in children born extremely preterm: the EPICure study. Am J Respir Crit Care Med 2010;182:237-45.

21 Northway WH Jr, Moss RB, Carlisle KB, et al. Late pulmonary sequelae of bronchopulmonary dysplasia. N Engl J Med 1990;323:1793-9.

22 McLeod A, Ross P, Mitchell S, et al. Respiratory health in a total very low birthweight cohort and their classroom controls. Arch Dis Child 1996;74:188-94

23 Kennedy JD, Edward LJ, Bates DJ, et al. Effects of birthweight and oxygen supplementation on lung function in late childhood in children of very low birth weight. Pediatr Pulmonol 2000;30:32-40.

24 Gross SJ, lannuzzi DM, Kveselis DA, et al. Effect of preterm birth on pulmonary function at school age: a prospective controlled study. J Pediatr 1998;133:188-92.

25 Blayney $\mathrm{M}$, Kerem $\mathrm{E}$, Whyte $\mathrm{H}$, et al. Bronchopulmonary dysplasia: improvement in lung function between 7 and 10 years of age. J Pediatr 1991;118:201-6.

26 Koumbourlis AC, Motoyama EK, Mutich RL, et al. Longitudinal follow-up of lung function from childhood to adolescence in prematurely born patients with neonatal chronic lung disease. Pediatr Pulmonol 1996:21:28-34.

27 Filippone M, Sartor M, Zacchello F, et al. Flow limitation in infants with bronchopulmonary dysplasia and respiratory function at school age. Lancet 2003;361:753-4

28 Baraldi E, Filippone M, Trevisanuto $D$, et al. Pulmonary function until two years of life in infants with bronchopulmonary dysplasia. Am J Respir Crit Care Med 1997:155:149-55.

29 Chan KN, Noble-Jamieson CM, Elliman A, et al. Lung function in children of low birth weight. Arch Dis Child 1989;64:1284-93.

30 Kitchen WH, Olinsky A, Doyle LW, et al. Respiratory health and lung function in 8 -year-old children of very low birth weight: a cohort study. Pediatrics 1992:89:1151-8. 


\section{Paediatric lung disease}

31 Doyle LW, Cheung MM, Ford GW, et al. Birth weight $<1501 \mathrm{~g}$ and respiratory health at age 14. Arch Dis Child 2001;84:40-4.

32 Svanes C, Sunyer J, Plana E, et al. Early life origins of chronic obstructive pulmonary disease. Thorax 2010;65:14-20.

33 Shaheen SO, Barker DJ, Holgate ST. Do lower respiratory tract infections in early childhood cause chronic obstructive pulmonary disease? Am I Respir Crit Care Med 1995;151:1649-51.
34 Peat JK, Woolcock AJ, Cullen K. Rate of decline of lung function in subjects with asthma. Eur J Respir Dis 1987;70:171-9.

35 Rijcken B, Weiss ST. Longitudinal analyses of airway responsiveness and pulmonary function decline. Am J Respir Crit Care Med 1996;154(6 Pt 2): S246-9.

36 Wohl ME. Bronchopulmonary dysplasia in adulthood. N Engl J Med 1990;323:1834-6. 